\title{
Exhaled 8-isoprostane as a new non-invasive biomarker of oxidative stress in cystic fibrosis
}

Paolo Montuschi, Sergei A Kharitonov, Giovanni Ciabattoni, Massimo Corradi, Liesbeth van Rensen, Duncan M Geddes, Margaret E Hodson, Peter J Barnes

\begin{abstract}
Background-Cystic fibrosis is characterised by oxidative stress in the airways. Isoprostanes are prostaglandin isomers formed by free radical catalysed peroxidation of arachidonic acid. 8-Isoprostane is increased in interstitial lung diseases, asthma, chronic obstructive pulmonary disease, and adult respiratory distress syndrome. Exhaled nitric oxide (NO) and carbon monoxide (CO) are biomarkers of inflammation and oxidative stress in the airways, respectively.
\end{abstract}

Methods-Concentrations of 8-isoprostane in the breath condensate of 10 normal subjects and 19 patients with stable cystic fibrosis were measured using an enzyme immunoassay (EIA). Breath condensate is a non-invasive method of collecting airway secretions. Exhaled nitric oxide (NO) and carbon monoxide (CO) levels were measured by a chemiluminescence analyser.

Results-Concentrations of 8-isoprostane in the breath condensate of patients with stable cystic fibrosis were increased about threefold compared with normal subjects (42.7 (4.5) $\mathrm{pg} / \mathrm{ml}$ vs $15.2 \quad(1.7) \mathrm{pg} / \mathrm{ml}$; $\mathrm{p}<0.005,95 \%$ CI 14.6 to 40.9$)$. 8-Isoprostane concentrations were negatively correlated with forced expiratory volume in one second in patients with cystic fibrosis $(r=-0.61 ; p<0.005)$. Exhaled CO was also increased in patients with cystic fibrosis compared with normal subjects (6.7 (1.2) ppm vs 2.9 (0.3) ppm; p<0.05, 95\% CI 0.2 to 7.4$)$. 8-Isoprostane concentrations were significantly correlated with CO levels $(r=0.66 ; \mathrm{p}<0.002)$.

Conclusions-The results of this study show that oxidative stress is increased in cystic fibrosis and may be quantified by measuring 8-isoprostane concentrations in breath condensate.

(Thorax 2000;55:205-209)

Keywords: cystic fibrosis; 8-isoprostane; oxidative stress

of Medicine, Catholic

University of the

Sacred Heart, Roma,

Italy

P Montuschi

G Ciabattoni

Correspondence to:

Professor P J Barnes

Received 12 July 1999

Returned to authors

20 September 1999

Revised manuscript received

5 November 1999

Accepted for publication

25 November 1999

Patients with cystic fibrosis have increased oxidative stress and a reduced antioxidant capacity. ${ }^{12}$ The frequent bronchopulmonary infections that are characteristic of cystic fibrosis activate and increase the numbers of neutrophils recovered from lungs of patients with cystic fibrosis. ${ }^{3}$ Activated neutrophils are the major source of free radicals. ${ }^{4}$ Biomarkers of oxidative stress are increased in plasma, ${ }^{5}$ bronchoalveolar lavage (BAL) fluid, ${ }^{6}$ and sputum of patients with cystic fibrosis, ${ }^{7}$ supporting a pathophysiological role for free radicals in this disease. Definitive evidence for this role has been hampered by the limitations of currently available methods to measure oxidative stress in vivo. ${ }^{8}$

Isoprostanes have recently been used to quantify oxidative stress in vivo. Measurements of these compounds in biological fluids may provide a quantitative index of oxidant stress in vivo. ${ }^{8}$ Isoprostanes are free radical catalysed products of arachidonic acid formed in situ in the cell membrane phospholipids, from which they are cleaved by phospholipase $\mathrm{A}_{2} \cdot{ }^{9}{ }^{10}$ Due to their stability, specificity for lipid peroxidation, in vivo production, and relative abundance in biological fluids, the isoprostanes are among the most reliable biomarkers of lipid peroxidation and oxidative stress. ${ }^{8}$ 8-Isoprostane, a member of the F2 isoprostane class, has been detected in plasma and urine in humans and its levels are increased in pathophysiological conditions in which oxidative stress is increased, such as cigarette smoking and scleroderma. ${ }^{10-13}$ We have found increased concentrations of 8-isoprostane in the BAL fluid of patients with interstitial lung diseases..$^{14}$ 8-Isoprostane concentrations are also increased in the urine of patients with chronic obstructive pulmonary disease (COPD) and in exhaled breath condensate in patients with adult respiratory distress syndrome (ARDS) and asthma. ${ }^{15-17}$ Recently, increased 8-isoprostane concentrations were reported in the plasma of patients with cystic fibrosis. ${ }^{18}$

In this study we have compared 8-isoprostane concentrations in the breath condensate of patients with stable cystic fibrosis with those in normal subjects. Breath condensate is a non-invasive method of collecting airway secretions. ${ }^{19}$ The aim of this study was to provide a non-invasive approach to direct measurement of oxidant stress in the lungs of patients with cystic fibrosis.

\section{Methods}

PATIENTS
Ten healthy subjects and 19 patients with stable cystic fibrosis were included in the study (table 1). Patients with cystic fibrosis were attending an outpatient clinic at the Royal Brompton Hospital in London for a regular (six monthly) check up and did not present with chest infections or any other specific problems. The study groups were matched for age. All study subjects were screened for active smoking by measuring urinary conitine levels (data not shown) and none was found to 
Table 1 Patient characteristics

\begin{tabular}{|c|c|c|}
\hline & Normal subjects & Cystic fibrosis \\
\hline $\begin{array}{l}\text { Number } \\
\text { Age (years) } \\
\text { Sex }(\mathrm{F} / \mathrm{M}) \\
\text { FEV }_{1}(\% \text { predicted }) \\
\text { FVC }(\% \text { predicted }) \\
\text { ESR }(\mathrm{mm} / \mathrm{h}) \\
\text { WBC }\left(\times 10^{9} / 1\right)\end{array}$ & $\begin{array}{l}10 \\
32(1.8) \\
4 / 6 \\
98(6.5) \\
101(5.5)\end{array}$ & $\begin{array}{l}19 \\
28(2.1) \\
11 / 8 \\
49.8(4.2)^{\star \star} \\
77.0(5.7)^{\star} \\
17.1(3.3) \\
9.4(2.9)\end{array}$ \\
\hline
\end{tabular}

smoke. Patients with cystic fibrosis had typical clinical features of the disease, including a positive sweat chloride test, and all were chronically infected with Pseudomonas aeruginosa. Patients infected with Burkholderia cepacia were excluded from the study. Five patients were being treated with inhaled glucocorticoids (beclometasone dipropionate $0.8-2 \mathrm{mg} /$ day, budesonide $2 \mathrm{mg} /$ day, fluticasone $1 \mathrm{mg} /$ day) and five patients were taking oral glucocorticoids (prednisolone 4-15 mg/day). Patients treated with oral steroids had poorer lung function (mean (SE) forced expiratory volume in one second $\left(\mathrm{FEV}_{1}\right) 28.9$ (3.5)\% predicted) than patients treated with inhaled steroids $\left(\mathrm{FEV}_{1} 45.7\right.$ (5.0)\% predicted) or steroid naive patients $\left(\mathrm{FEV}_{1} 60.9\right.$ (3.3)\% predicted). One patient treated with inhaled steroids and two treated with oral steroids had allergic bronchopulmonary aspergillosis. Two other patients had arthritis. None of the steroid naive patients had allergic bronchopulmonary aspergillosis or arthritis. Treatment accepted for the study consisted of antibiotics (flucoxacillin, colomycin, gentamicin, tobramycin) and bronchodilators ( $\beta_{2}$ adrenergic drugs, anticholinergics). Five patients were taking DNAse (Dornase alfa) $2.5 \mathrm{mg} /$ day. No patient was receiving ibuprofen or macrolides.

Informed consent was obtained from all subjects and the study was approved by the ethics committee of the Royal Brompton Hospital and Harefield Trust.

\section{PULMONARY FUNCTION}

Pulmonary function tests were performed on the same day as the measurement of $\mathrm{NO}$ and CO. $\mathrm{FEV}_{1}$ and forced vital capacity (FVC) were measured using a dry spirometer (Vitalograph Ltd, Buckingham, UK) and the best value of the three manoeuvres was expressed as a percentage of the predicted value.

8-Isoprostane was measured within two weeks of the breath condensate sample collection.

MEASUREMENT OF EXHALED 8-ISOPROSTANE Breath condensate samples were collected using a specially designed glass condensing chamber. The condensing chamber contained a double wall glass and the inner side of the glass was cooled by ice. Breath condensate was collected between the two glass surfaces. Exhaled air entered and left the chamber through one-way valves at the inlet and at the outlet, keeping the chamber closed. After rinsing their mouths, subjects breathed tidally through a mouthpiece connected to the condenser for 15 minutes while wearing noseclips. Approximately $1 \mathrm{ml}$ of condensate was stored at $-70^{\circ} \mathrm{C}$ in a $2 \mathrm{ml}$ sterile plastic tube. ${ }^{19}$

8 -Isoprostane concentrations in breath condensate were measured by a specific enzyme immunoassay (EIA) kit (Cayman Chemical, Ann Arbor, Michigan, USA). Samples were collected and stored at $-70^{\circ} \mathrm{C}$ until assayed. The assay has been validated to obtain a high correlation (0.95) between added known amounts of 8-isoprostane and the concentration measured by EIA. This assay was directly validated by gas chromatography/mass spectrometry. The antiserum used in this assay has a $100 \%$ cross reactivity with 8 -isoprostane, $0.2 \%$ each with prostaglandins $\mathrm{PGF}_{2 \alpha}, \mathrm{PGF}_{3 \alpha}$, $\mathrm{PGE}_{1}$ and $\mathrm{PGE}_{2}$, and $0.1 \%$ each with 6-keto$\mathrm{PGF}_{1 \alpha}$. The detection limit of the assay is $4 \mathrm{pg} /$ $\mathrm{ml}$. The kit has been used to measure 8-isoprostane concentrations in breath condensate and in BAL fluid. ${ }^{15} 18$

The possible influence of the ventilation rate on 8-isoprostane concentrations in breath condensate was assessed. Normal volunteers breathed at 14 and 28 breaths/min for $15 \mathrm{~min}$ utes keeping the same tidal volume. There was no difference in the concentration of 8-isoprostane in the two samples collected from the same patient at the different ventilation rates $(15.8 \mathrm{pg} / \mathrm{ml}$ and $12.5 \mathrm{pg} / \mathrm{ml}, \mathrm{n}=6)$.

The intra-assay and interassay coefficients of variation were $5 \%$ and $6 \%$, respectively. Saliva contamination of breath condensate was ruled out by measuring amylase concentrations which were undetectable in six samples tested.

MEASUREMENT OF EXHALED NITRIC OXIDE

Exhaled NO was measured using a chemiluminescence analyser (model LR2000; Logan Research, Rochester, UK), sensitive to NO in concentrations from 1 to $5000 \mathrm{ppb}$ (by volume) and with a resolution of $0.3 \mathrm{ppb}$, which was designed for online recording of exhaled NO concentrations as previously described. ${ }^{20}$ The analyser was calibrated using a certified NO mixture (436 ppb) in nitrogen (BOC Special Gases, Guildford, UK). Measurements of exhaled NO were made by slow exhalation (5-6 1/min) from total lung capacity for 20-30 seconds against a resistance (3 $(0.4) \mathrm{mm} \mathrm{Hg}$ ) to prevent nasal contamination.

MEASUREMENT OF EXHALED CARBON MONOXIDE Exhaled $\mathrm{CO}$ was measured by an electrochemical $\mathrm{CO}$ monitor sensitive to $\mathrm{CO}$ from 0 to $500 \mathrm{ppm}$ by volume, adapted for online recording of $\mathrm{CO}$ concentrations and integrated with the chemiluminescence analyser (LR2000, Logan Research, Rochester, UK) to control exhalation parameters. The subjects exhaled slowly from functional vital capacity with a constant flow (5-6 1/min) against a resistance (3 (0.4) $\mathrm{mm} \mathrm{Hg}$ ) over 20-30 seconds into the analyser. Two successive recordings were made and mean values were used in all calculations. Ambient CO levels were recorded before each measurement. 


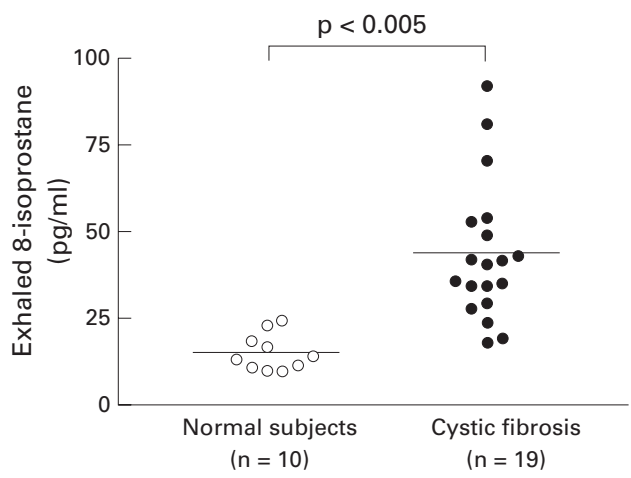

Figure 1 Concentrations of 8-isoprostane in breath condensate of normal subjects and patients with cystic fibrosis. The horizontal bars indicate mean levels.

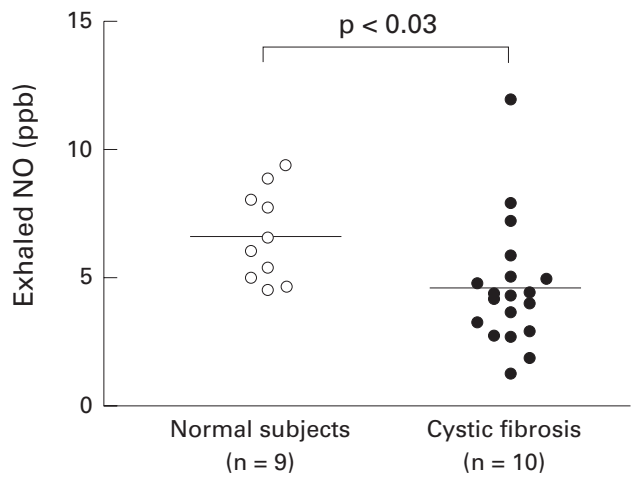

Figure 2 Concentrations of nitric oxide (NO) in exhaled air of normal subjects and patients with cystic fibrosis. The horizontal bars indicate mean levels.

STATISTICAL ANALYSIS

For parametric data the Student's unpaired $t$ test was used to compare groups. Linear regression analysis was used to assess the relationship between 8-isoprostane concentrations in breath condensate and exhaled gases or $\mathrm{FEV}_{1}$. All data were expressed as mean (SE) values and $p$ values of $<0.05$ were considered significant.

\section{Results}

The clinical data of the healthy subjects and patients with cystic fibrosis are summarised in table 1. 8-Isoprostane was measurable in breath condensate of healthy subjects $(15.2(1.7) \mathrm{pg} /$ $\mathrm{ml}$ ) and was increased 2.8-fold in patients with cystic fibrosis (42.7 (4.5) pg/ml; p <0.005, 95\% CI 14.6 to 40.9 ; fig 1 ). Concentrations of 8 -isoprostane in breath condensate were similar in untreated patients (37.7 (6.4) $\mathrm{pg} / \mathrm{ml}, \mathrm{n}=9)$ and those treated with inhaled $(45.1(11.8) \mathrm{pg} /$ $\mathrm{ml}, \mathrm{n}=5 ; \mathrm{p}=0.56)$ or oral steroids (49.4 (6.1) $\mathrm{pg} / \mathrm{ml}, \mathrm{n}=5 ; \mathrm{p}=0.26$ ). We also measured exhaled $\mathrm{NO}$ and $\mathrm{CO}$ in the same study groups as biomarkers of airway inflammation and oxidative stress, respectively. NO was significantly decreased in patients with cystic fibrosis compared with healthy subjects $(6.5(0.6)$ ppb vs 4.4 (0.6) ppb, $95 \%$ CI -3.9 to -0.2 , p<0.03; fig 2) whereas exhaled $\mathrm{CO}$ was increased in the patients with cystic fibrosis $(2.9(0.3) \mathrm{ppm}$ vs 6.7 (1.2) ppm, p<0.05; fig 3). NO levels were similar in steroid naive patients $(4.3(0.7) \mathrm{ppb}, \mathrm{n}$ $=9)$ and in patients treated with inhaled (4.9 (0.9) ppb, $\mathrm{n}=5, \mathrm{p}=0.83$ ) or oral steroids (3.7 (1.1) $\mathrm{ppb}, \mathrm{n}=5, \mathrm{p}=0.57)$. There was no differ-

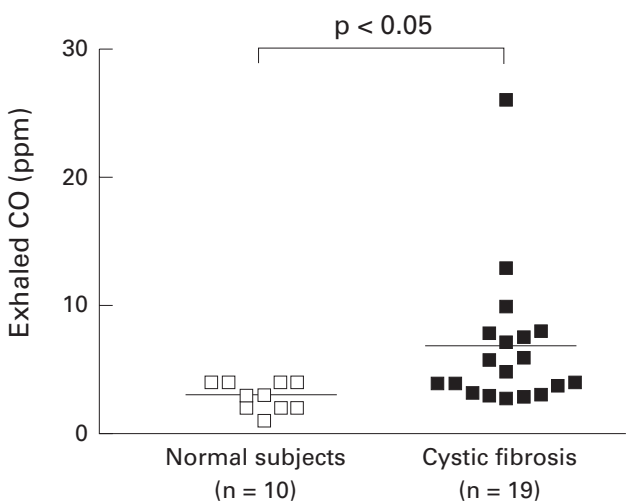

Figure 3 Concentrations of carbon monoxide (CO) in exhaled air of normal subjects and patients with cystic fibrosis. The horizontal bars indicate mean levels.
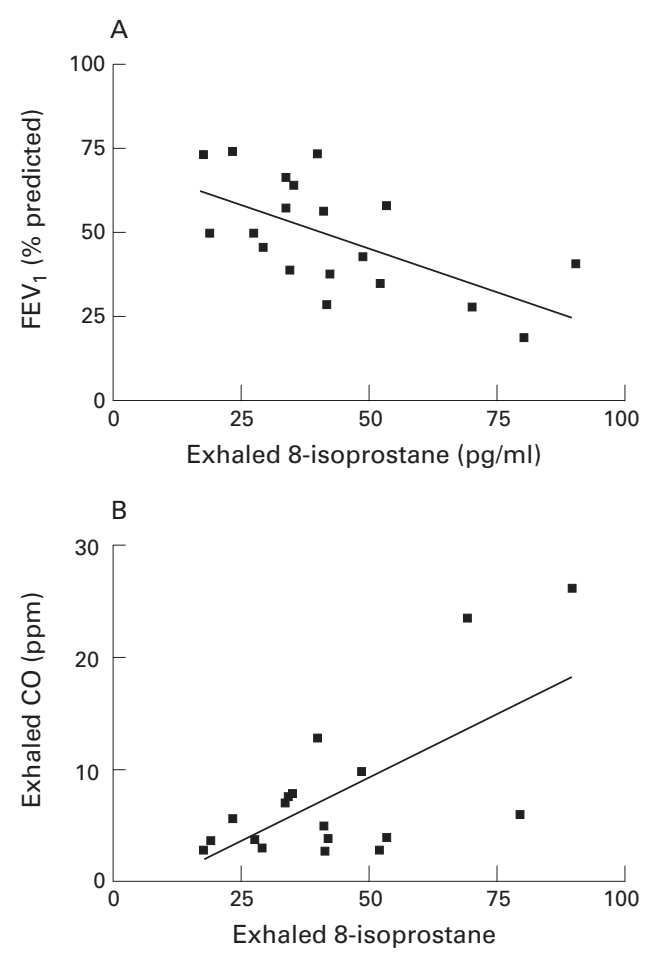

Figure 4 (A) Correlation between 8-isoprostane concentrations in breath condensate and forced expiratory volume in one second (FEV) in patients with cystic fibrosis $(r=-0.61 ; p<0.005)$. (B) Correlation between 8-isoprostane concentrations in breath condensate and carbon monoxide in exhaled air in patients with cystic fibrosis $(r=0.66 ; p<0.002)$.

ence in $\mathrm{CO}$ levels between untreated patients (5.3 (1.1) ppm, $\mathrm{n}=9$ ) and those treated with inhaled $(10.3(4.0) \mathrm{ppm}, \mathrm{n}=5, \mathrm{p}=0.15)$ or oral steroids (5.5 (1.4) ppm, $\mathrm{n}=5, \mathrm{p}=0.90)$. The concentration of 8-isoprostane in breath condensate was negatively correlated with $\mathrm{FEV}_{1}(r=$ $-0.61 ; \mathrm{p}<0.005$, fig $4 \mathrm{~A}$ ) and positively correlated with exhaled CO levels $(r=0.66 ; \mathrm{p}<0.002$, fig $4 B)$ in patients with cystic fibrosis. No correlation was found between age, sex, FVC, or exhaled NO levels and the concentration of 8 -isoprostane in breath condensate (data not shown).

\section{Discussion}

8-Isoprostane, the most well characterised compound belonging to the F2-isoprostanes, a group of prostaglandin $\mathrm{F}_{2 \alpha}$ stereoisomers, is 
formed in vivo by reactive oxygen species (ROS) peroxidation of arachidonic acid, independent of the action of cyclo-oxygenase. ${ }^{11}$ Although 8-isoprostane can be produced by cyclo-oxygenase-1 and/or cyclo-oxygenase- 2 activity in some cells and tissues, both in vitro and in vivo, ${ }^{21-23}$ its production in vivo in humans is mainly derived from lipoperoxidation due to ROS. ${ }^{16}$ For this reason, measurement of 8-isoprostane levels in biological fluids has been considered an ideal method of quantifying oxidative stress in different pathophysiological conditions. ${ }^{9}$

In this study we have shown that 8-isoprostane is measurable in the breath condensate of normal subjects. The levels of 8 -isoprostane in these subjects were similar to those found in the breath condensate by Montuschi et $a l^{17}$ using gas chromatography/mass spectrometry. Patients with cystic fibrosis had 8 -isoprostane levels 2.8 -fold higher than normal subjects, indicating that oxidative stress, as reflected by 8 -isoprostane concentrations in breath condensate, is increased in patients with cystic fibrosis. These results are in agreement with a recent study which reported increased plasma concentrations of 8-isoprostane in patients with cystic fibrosis. ${ }^{18}$ Measurement of 8 -isoprostane in plasma reflects systemic oxidative stress, whereas measurement of 8 -isoprostane in the exhaled breath condensate is more likely to reflect lipoperoxidation that occurs in the lungs. Although numbers are small, subgroup analysis suggests that there was no difference in 8-isoprostane levels between untreated patients with cystic fibrosis and those treated with steroids. However, sample size and lack of homogeneity prevent definite conclusions on the role of glucocorticoids in modulating 8-isoprostane concentrations in breath condensate. Larger numbers and homogeneous groups are needed to confirm or refute these preliminary findings. In contrast to other inflammatory airway diseases such as interstitial lung diseases and COPD, ${ }^{15}{ }^{16} 8$-isoprostane levels in breath condensate were inversely correlated with $\mathrm{FEV}_{1}$ in patients with cystic fibrosis, suggesting that an increase in oxidant stress may lead to a deterioration of lung function.

Consistent with other studies, ${ }^{24} 25$ exhaled NO levels were lower and CO levels were higher in patients with cystic fibrosis than in normal subjects. The low exhaled $\mathrm{NO}$ values could be due to the trapping effect of the viscous airway secretions in these patients or to a scavenging effect on $\mathrm{NO}$ as a result of enhanced ROS formation. ${ }^{26}{ }^{27} \mathrm{~A}$ deficiency in inducible NO synthase could also account for this finding. ${ }^{28}$ Unlike other respiratory diseases such as asthma in which exhaled NO reflects airway inflammation, ${ }^{29}$ low NO levels in patients with cystic fibrosis preclude the possibility of using it as a biomarker of inflammation in this disease. Exhaled CO, another biomarker of inflammation and oxidative stress, is increased more than twofold compared with normal subjects, further supporting a role for ROS in the pathophysiology of cystic fibrosis. The significant correlation between 8-isoprostane in breath condensate and exhaled $\mathrm{CO}$ indicates that these two biomarkers may have a similar biological significance in reflecting overproduction of ROS in cystic fibrosis. A similar increase in 8-isoprostane and CO levels was previously reported in patients with severe asthma. ${ }^{18}$ Considering the protective role of hemoxygenase activation, enhanced $\mathrm{CO}$ production could represent a mechanism to counteract the oxidative damage. ${ }^{30}$ Large controlled studies are required to establish the role of steroid treatment in modulating exhaled $\mathrm{CO}$ levels. Nothing is known about the possible role of 8-isoprostane as a mediator of oxidative stress in cystic fibrosis, although this compound may have a role in the pathophysiology of oxidant damage due to its biological actions. ${ }^{9}$

In conclusion, we have shown that lipid peroxidation and oxidative stress are increased in patients with cystic fibrosis, as reflected by increased 8-isoprostane concentrations in breath condensate. Measurement of 8 -isoprostane by this non-invasive approach may provide the rational basis for dose finding studies of antioxidants and an important end point in clinical trials of these drugs in cystic fibrosis.

Dr Paolo Montuschi is recipient of Research Fellowship from the National Research Council of Italy.

1 Brown RK, Wyatt H, Price JF, et al. Pulmonary dysfunction in cystic fibrosis is associated with oxidative stress. Eur in cystic fibrosis is as

2 McGrath LT, Mallon P, Dowey L, et al. Oxidative stress during acute respiratory exacerbations in cystic fibrosis. Thorax 1999;54:518-23.

3 Holsclaw DS. Cystic fibrosis and pulmonary involvement from multiple perspectives. Semin Respir Infect 1993;7:14150

4 Babior BM. The respiratory burst oxidase. Trends Biomed Sci 1987;12:241-3.

5 Brown RK, Kelly FJ. Evidence for increased oxidative damage in patients with cystic fibrosis. Pediatr Res 1994;36:48793.

6 Hull J, Vervaart P, Grimwood K, et al. Pulmonary oxidative stress response in young children with cystic fibrosis. Thorax 1997;52:557-60.

7 Witko-Sarasat V, Delacourt C, Rabier D, et al. Neutrophilderived long-lived oxidants in cystic fibrosis sputum. Am $\mathcal{F}$ Respir Crit Care Med 1995;152:1910-16.

8 Moore K, Roberts LJ. Measurement of lipid peroxidation. Moore K, Roberts LJ. Measure
Free Radic Res 1998;28:659-71.

Free Radic Res 1998;28:659-71.
9 Morrow JD, Awad JA, Boss HJ, et al. Non-cyclooxygenase derived prostanoids (F2-isoprostanes) are formed in situ on phospholipids. Proc Natl Acad Sci USA 1992;89:107215.

10 Morrow JD, Hill KE, Burk RF, et al. A series of prostaglandin F2-like compounds are produced in vivo in humans by a non-cyclooxygenase, free-radical-catalyzed mechanism. Proc Natl Acad Sci USA 1990;87:9383-7.

11 Wang Z, Ciabattoni G, Creminon C, et al. Immunological characterization of urinary 8-epi-prostglandin $\mathrm{F}_{2 \alpha}$ excretion in man. F Pharmacol Exp Ther 1995;275:94-100.

12 Morrow JD, Frei B, Longmire AW, et al. Increase in circulating products of lipid peroxidation (F2-isoprostanes) in ing products of lipid peroxidation (F2-1s

13 Stein CM, Tanner SB, Awad JA, et al. Evidence for a free radical-mediated injury (isoprostane overproduction) in radical-mediated injury (isoprostane overproduc

14 Montuschi P, Ciabattoni G, Paredi P, et al. 8-isoprostane as a biomarker of oxidative stress in interstitial lung disease. Am $\mathcal{F}$ Respir Crit Care Med 1998;158:1524-7.

15 Praticò P, Basili S, Vieri M, et al. Chronic obstructive pulmonary disease is associated with an increase in urinary levels of isoprostane F $2 \alpha$-III, an index of oxidant stress. Am 7 Respir Crit Care Med 1998;158:1709-14.

16 Carpenter CT, Price PV, Christman BW. Exhaled breath condensate isoprostanes are elevated in patients with acute lung injury and ARDS. Chest 1998;114:1653-9.

17 Montuschi P, Corradi M, Ciabattoni G, et al. Increased 8 -isoprostane, a marker of oxidative stress, in exhaled condensate of asthmatics patients. Am f Respir Crit Care Med 1999; 160:216-20.

18 Collins CE, Quaggiotto P, Wood L, et al. Elevated plasma levels of $\mathrm{F}_{2 \alpha}$ isoprostane in cystic fibrosis. Lipids 1999;34: 551-6. 
19 Loukides S, Horvath I, Wodehouse T, et al. Elevated levels of expired breath hydrogen peroxide in bronchiectasis. Am of expired breath hydrogen peroxide in

20 Kharitonov SA, Chung FK, Evans DJ, et al. The elevated level of exhaled nitric oxide in asthmatic patients is mainly derived from the lower respiratory tract. Am $\mathcal{F}$ Respir Crit Care Med 1996;153:1773-80.

21 Praticò D, Lawson JA, FitzGerald GA. Cyclooxygenasedependent formation of the isoprostane, 8-epi-prostglandin $\mathrm{F}_{20}$. F Biol Chem 1995;270:9800-8

22 Klein T, Reutter F, Schweer H, et al. Generation of the isoprostane 8-epi-prostglandin $\mathrm{F}_{2}$ alpha in vitro and in vivo via the cyclooxygenases. F Pharmacol Exp Ther 1997;282: $1658-65$

23 Montuschi P, Currò D, Ragazzoni E, et al. Anaphylaxis increases 8-iso-prostaglandin $\mathrm{F}_{2 \alpha}$ release from guine-pig lung in vitro. Eur $\mathcal{F}$ Pharmacol 1999;365:59-64.

24 Grasemann $\mathrm{H}$, Michler $\mathrm{E}$, Wallot $\mathrm{M}$, et al. Decreased concentration of exhaled nitric oxide (NO) in patients with cystic fibrosis. Pediatr Pulmonol 1997;24:173-7.
25 Paredi P, Montuschi P, Shaha PL, et al. Exhaled carbon monoxide is elevated in cystic fibrosis. A new test for disease monitoring? Eur Respir $\mathcal{F}$ 1998;12 (Suppl 28):235s.

26 Ho LP, Innes JA, Greening AP. Nitrite levels in breath condensate of patients with cystic fibrosis is elevated in contrast to exhaled nitric oxide. Thorax 1998;53:680-4.

27 Jones KL, Bryan TW, Jinkins PA, et al. Superoxide causes a reduction in nitric oxide gas and an increase in nitrate. Am f Respir Crit Care Med 1998;157:A132.

28 Kelley TJ, Drumm ML. Inducible nitric oxide synthase expression is reduced in cystic fibrosis murine and human airway epithelial cells. F Clin Invest 1998;102:1200-7.

29 Kharitonov SA, Yates D, Robbins RA, et al. Increased nitric oxide in exhaled air of asthmatic patients. Lancet 1994;343: $133-5$.

30 Choi AM, Alam J. Heme oxygenase-1: function, regulation, and implication of a novel stress-inducible protein in oxidant-induced lung injury. Am $\mathcal{f}$ Respir Cell Mol Biol 1996;15:9-19. 